\title{
GLOBALIZAÇÃO E LEGITIMIDADE CONSTITUCIONAL
}

\section{Cesar Antonio Serbena}

Professor da UFPR, Doutorando em Direito pela UFPR.

SUMÁRIO: Introdução; I - Antecedentes histórico-filosóficos do cosmopolitismo constitucional; II - É a globalização causa de uma "crise" da legitimidade constitucional?; Conclusão; Referências bibliográficas.

\section{INTRODUÇÃO}

É incontável o número de trabalhos e de artigos que nos últimos anos têm surgido em várias disciplinas, como a administração, a economia e o direito, sobre o tema globalização. $\mathrm{O}$ assunto, de tão comentado, criou em torno de si mesmo uma espécie de auto-definibilidade, como se, ao mencioná-lo, qualquer indivíduo entendesse do que se está falando. Ao mesmo tempo, tornou-se corriqueiro aceitar a globalização como natural, como inevitável, assim como seria perfeitamente natural a obrigação de entender e aprender o inglês como o novo idioma destes novos tempos.

Dessa maneira, enfrentar e propor-se a refletir sobre a globalização e o direito constitucional, sem cair na superficialidade teórica do senso comum dominante e cristalizado sobre o tema, é uma tarefa imperativa e obrigatória, mas não por isso simples. Há um perigo correlato, mas com significado inverso, à superficialidade que consiste em, ao criticar, ou rejeitar, ou minimizar a globalização, simplificá-la para facilitar a crítica, não atingindo os seus fundamentos. Poderíamos denominar esta superficialidade teórica de superficialidade negativa.

Desse modo, é necessário procurar entender a ambígua globalização e evitar ambas as superficialidades. Somente desse modo é possível acrescentar algo relevante teoricamente e que possa contribuir para o entendimento do tema.

Basicamente os objetivos do presente trabalho são dois, bastante modestos: num primeiro momento, apresentar os antecedentes históricos e filosóficos da concepção, tipicamente ocidental, de uma ordem jurídica internacional, racional e, do ponto de vista do indivíduo, universal; num segundo momento, responder à seguinte questão: seria a globalização verdadeiramente a fonte de uma crise de legitimidade do Estado contemporâneo e, por conseqüência, da força normativa das constituições em geral e da brasileira em particular?

Para o exame do primeiro objetivo, expomos os principais tópicos da filosofia política de IMMANUEL KANT no que se refere a um tema bastante conhecido de sua filosofia, a paz perpétua. Justifica-se a escolha de KANT pela ampla síntese por ele fornecida do ideário jurídico do iluminismo. Outros filósofos da época moderna também são de importância fundamental, como ROUSSEAU, que mais influência teve sobre 
KANT, mas somente nele temos filosófica e ideologicamente sistematizados praticamente todos os objetivos iluministas, como a consolidação da liberdade individual, do Estado limitado politicamente e da razão como fundamento da vida prática e da ordem internacional. Um exame do pensamento dos filósofos modernos estaria fora do alcance e dos objetivos deste trabalho.

A resposta à segunda questão defendida neste trabalho é negativa. Através do exame de diferentes autores e de uma rápida avaliação e comparação de suas teses, além de uma breve consideração sobre a situação atual, concluímos pela negativa à pergunta formulada.

\section{I - ANTECEDENTES HISTÓRICO-FILOSÓFICOS DO COSMOPOLITISMO CONSTITUCIONAL}

A idéia de uma ordem jurídica internacional, da proteção universal dos direitos individuais ou de uma "cidadania" global não são novas no ideário ocidental. O que denominamos atualmente de globalização já foi projetado e pensado na filosofia política européia, mais nitidamente no movimento iluminista.

Como é conhecido, os ideais do iluminismo ainda se projetam sobre a cultura ocidental atual. O que os iluministas chamavam de direitos naturais desenvolveu-se historicamente até o que hoje denominamos direitos humanos. Em todo esse desenvolvimento está subjacente a idéia de que o direito e a história não se desenvolvem ao acaso, mas seguem algum tipo de racionalidade.

Convém examinar rapidamente a doutrina do último filósofo do iluminismo, que produziu sua melhor síntese e projetou seus ideais para o futuro, sentidos de maneira indireta na doutrina jurídica atual: IMMANUEL KANT.

KANT, dentro do contexto de uma Europa que vivia um período conturbado pelas guerras posteriores à Revolução Francesa, escreveu um ensaio intitulado Sobre a paz perpétua e posteriormente um capítulo da Metafísica dos costumes com o título " $\mathrm{O}$ direito dos povos". Nesses dois escritos, KANT formulou sua teoria da paz perpétua, que, segundo $\mathrm{BOBBIO},{ }^{1}$ está fundamentada em quatro pontos principais:

1. os Estados nas suas relações externas vivem ainda num estado não jurídico ou um estado jurídico provisório;

2. o estado de natureza é um estado de guerra e, conseqüentemente, um estado injusto, como é injusto o estado de natureza entre os indivíduos;

3. sendo este estado injusto, KANT considera que os Estados têm o dever de sair deste estado e fundar uma federação de Estados, segundo a idéia de um contrato social originário, pautado pela obrigação recíproca de não se intrometer nos problemas internos uns dos outros e proteger-se contra os assaltos de um inimigo externo;

1 Para a redação deste capítulo, baseamo-nos na obra de NORBERTO BOBBIO, Direito e estado no pensamento de Emanuel Kant. 
4. a federação de Estados não institui um poder soberano, não dá origem a um Estado acima dos outros Estados, mas assume a figura de uma associação na qual os componentes permanecem num nível de colaboração entre iguais.

KANT concebeu que seria possível implementar esta confederação de Estados se fixando em alguns pontos aos quais ele dá a forma de artigos de um tratado imaginário, distinguindo seis artigos preliminares, que estabelecem as condições necessárias para que sejam eliminadas as principais razões de guerra entre os Estados, e três artigos definitivos, nos quais são estabelecidas as condições necessárias para o estabelecimento de uma paz duradoura.

Os seis artigos preliminares, segundo KANT, são:

1. Nenhum tratado de paz pode ser considerado como tal, se é feito com a tácita reserva de pretextos para uma guerra futura.

Para KANT, um tratado de paz não deve conter nem o pedido de ressarcimento das despesas de guerra, pois neste caso o Estado vencedor seria juiz em causa própria, nem retirar aos súditos do Estado vencido a liberdade, pois esta é um direito natural dos indivíduos e dos povos.

2. Nenhum Estado independente pode ser adquirido por outro através de sucessão hereditária, troca, compra ou doação.

Nesse item, KANT combate a teoria do estado patrimonial, segundo a qual o território do Estado é considerado propriedade do príncipe, e dele o príncipe pode dispor como um dominus (domínio) dispõe da própria posse.

3. Os exércitos permanentes devem com o tempo desaparecer inteiramente.

KANT concebia o desarmamento como condição para a obtenção da paz.

4. Não devem ser contraídas dívidas públicas em vista de uma ação a ser empreendida no exterior.

BOBBIO explica que "KANT, referindo-se ao sistema de dívidas públicas, introduzido pela primeira vez na Inglaterra por GUILHERME III, quer evitar o perigo implícito no aumento indefinido da dívida pública, que leva o Estado a possuir uma perigosa força financeira, ameaça perpétua, direta ou indireta, de guerra". ${ }^{2}$

5. Nenhum Estado deve intrometer-se, através da força, na constituição e no governo de um outro Estado.

KANT reforça nesse artigo o princípio da não-intervenção.

6. Nenhum Estado em guerra com outro deve permitir atos de hostilidade que tornariam impossível a confiança recíproca na paz futura.

KANT cita o recurso a assassinos, envenenadores, espiões e instigação à traição. 
Os três artigos definitivos são:

1. A constituição de qualquer Estado deve ser republicana.

Cabe aqui um esclarecimento necessário sobre o sentido do termo "república" no pensamento político kantiano. Para esse clássico pensador, o estado republicano é o estado ideal do ponto de vista político.

KANT admite que para distinguir as formas de governo podem ser adotados dois critérios diferentes de distinção: ou se leva em conta a diferença das pessoas que detêm o poder soberano, ou se leva em conta a diferença no modo de governar. Com base no primeiro critério, o Estado é caracterizado segundo o fato de que o governo seja regido por um, por poucos, ou por todos, e tem-se assim as três formas tradicionais (autocracia, aristocracia e democracia), conhecidas já na filosofia política e estudadas na Política de Aristóteles. Com base no segundo critério (o modo de governar), os Estados são caracterizados segundo o fato de que o governo, seja ele um, poucos ou muitos, exerça o poder legal ou arbitrariamente e aqui reside a distinção entre república e despotismo.

No pensamento de KANT, a república não é contraposta à monarquia, mas ao despotismo. Ela não é uma das formas tradicionais de governo, que se distingue com relação às pessoas, mas representa a forma boa de governo contraposta à má. Não devemos esquecer que KANT assumia a liberdade do indivíduo como o principal direito natural e ao qual os demais poderiam ser reduzidos. A república seria o regime político que assegura a liberdade do cidadão.

E uma vez que as duas distinções, a primeira baseada na diferença dos que governam e a segunda baseada na diferença do modo de governar, não coincidem, não há impedimento para se admitir uma república democrática, uma república aristocrática ou uma república monárquica. Esta última era o regime político preferido de KANT, como pode ser visto em seu ensaio $O$ que é o iluminismo?.

Em poucas palavras, o Estado com uma constituição republicana é um Estado que, independentemente de ser uma monarquia ou aristocracia ou democracia, assegura um modo de governo não despótico, não arbitrário e no qual vigora o princípio da autonomia legislativa.

2. O direito internacional deve fundamentar-se numa federação de Estados livres.

O pacifismo político de KANT desemboca num pacifismo jurídico. A república é uma condição necessária, porém não suficiente para a paz perpétua. É também necessário que as repúblicas originem uma federação, ou seja, que se obriguem a entrar numa constituição análoga à constituição civil na qual seja possível garantir para cada membro o próprio direito.

3. O direito cosmopolita deve ser limitado às condições de uma hospitalidade universal.

Como esclarece BOBBIO acerca desse artigo: "por 'direito cosmopolita' entende-se uma seção do direito diversa do direito internacional: dela KANT trata 
brevemente no final da Metafísica dos costumes. Enquanto o direito internacional regula as relações entre os Estados, e o direito interno regula as relações entre o Estado e os próprios cidadãos, o direito cosmopolita regula as relações entre um Estado e os cidadãos dos outros Estados (ou seja, os estrangeiros). A máxima fundamental do direito cosmopolita é que um estrangeiro que vai para o território de um outro Estado não deve ser tratado com hostilidade até o momento em que cometa atos hostis contra o Estado que o está hospedando. KANT justifica essa máxima com o direito que cabe a todos os homens de entrar em sociedade com os seus semelhantes, em virtude da posse comum originária de toda a superfície da terra. Mas nesse último artigo do seu projeto de paz perpétua, KANT estabelece um limite para esse direito de hospitalidade, ou pelo menos quer definir exatamente o âmbito dentro do qual pode ser exercido". ${ }^{3}$

O exame da teoria kantiana nos surpreende pela atualidade de suas considerações. É possível visualizar em sua teoria os fundamentos de uma ordem jurídica internacional, podendo-se até afirmar que esses fundamentos continuam os mesmos até os tempos atuais. Aquilo que ele denominou de uma hospitalidade universal, ou de um direito cosmopolita, transfigurou-se historicamente naquilo que conhecemos por direito internacional privado e no discurso atual sobre os direitos humanos, como sendo o mínimo de conteúdo jurídico a ser contemplado em qualquer ordem constitucional.

A teoria política kantiana projetou uma federação internacional de estados, tendo sido esta proposta concretizada no século XX com a criação dos organismos multilaterais.

É importante mencionar também que KANT, em diversas obras, como Idéia de uma história do ponto de vista cosmopolita e Se o gênero humano se encontra em progresso contínuo em direção ao melhor, manifestou-se favorável à idéia de que existe na história humana um progresso. Esse progresso pode ser medido ou valorado pelo desenvolvimento da liberdade e da razão, cujo fim último é a constituição de uma ordem jurídica fundada na liberdade e na paz (perpétua).

Portanto, como pretendemos ter demonstrado através do pensamento de KANT, a globalização, em seu aspecto cultural e jurídico, é uma conseqüência direta do iluminismo e do seu projeto histórico e filosófico.

\section{II - É A GLOBALIZAÇÃO CAUSA DE UMA “CRISE” DA LEGITIMIDADE CONSTITUCIONAL?}

Uma afirmação muito difundida atualmente é de que a margem de manobra dos Estados nacionais sofreu nas últimas décadas um drástico estreitamento e que os Estados nacionais estariam indefesos diante de processos "globais" incontroláveis ou irreversíveis e teriam ingressado em uma época de inevitável declínio.

Parece ser essa a opinião de DANIEL SARMENTO: 
“Observa-se, porém, que o caso do Estado-nação não está sendo acompanhado pelo surgimento de alguma outra instituição que possa legitimamente substituí-lo. E, evidentemente, a crise do Estado contagia a Constituição, que tende a perder a sua centralidade no processo de regulação da vida social. Este quadro se dramatiza na medida em que se constata a inexistência, no arsenal do direito contemporâneo, de outro instrumento que possa desempenhar o papel atribuído pela modernidade à Constituição. Assim, o futuro que se antevê para o constitucionalismo do próximo milênio é, no mínimo, incerto e nebuloso. (...) A mudança estrutural da ordem internacional é uma das causas mais visíveis do sepultamento definitivo da idéia de que o Estado é o titular do monopólio da produção de normas jurídicas. Com efeito, enquanto o Estado Nacional perde o viço, tragado pela força incoercível do processo de globalização econômica, se robustecem as instâncias supranacionais de poder."

Parece ser essa também a tese de JOSÉ EDUARDO FARIA. Sua análise é de que, face ao policentrismo que hoje caracteriza a economia globalizada, o direito positivo e suas instituições perdem uma parte significativa de sua jurisdição. Seria possível identificar um direito supra-estatal e um direito infra-estatal. O primeiro seria caracterizado pela polarização de diversos organismos multilaterais, como o Banco Mundial, o Fundo Monetário Internacional, a Organização Mundial do Comércio, o Banco de Compensações Internacionais e a Organização Mundial da Propriedade Intelectual. O segundo seria polarizado por formas inoficiais ou não oficiais de resolução dos conflitos, como usos, costumes, diferentes estratégias de mediação, negociação e conciliação, autocomposição de interesses e auto-resolução de divergências, arbitragens privadas ou mesmo a imposição da lei do mais forte nos guetos inexpugnáveis corolados pelo crime organizado e pelo narcotráfico, constituindo-se assim uma espécie de direito marginal.

Para esse autor: "a fragmentação geoespacial das atividades produtivas vem tornando possível uma ampliação sem precedentes do comércio intrafirmas, com importantes conseqüências para as engrenagens jurídicas do Estado-nação. Hoje, pelo menos $1 / 3$ das atividades e negócios das 37 mil empresas transnacionais que atuam na economia globalizada - por meio de 200 mil filiais e subsidiárias - é realizado entre elas próprias. Tal expansão do comércio intrafirmas abre caminho para a ruptura da centralidade e da exclusividade do direito positivo nacional. Editado sob a forma de uma ordem jurídica postulada como lógica, coerente e livre de ambigüidades ou antinomias, esse direito é desafiado por regras e procedimentos normativos espontaneamente forjados no sistema econômico. São direitos autônomos, como normas lógicas e processos próprios, entreabrindo a coexistência (por vezes sincrônica, por vezes conflitante) de diferentes normatividades; mais precisamente, de um pluralismo jurídico de natureza infra-estatal ou supra-estatal. É esse o caso, por exemplo, da lex mercatoria e (...) direito da produção". 5

4 SARMENTO, Daniel. Constituição e globalização: a crise dos paradigmas do direito constitucional, p. 24.

5 FARIA, José Eduardo. Direitos humanos e globalização econômica: notas para uma discussão, p. 45. 
As análises com relação aos procedimentos através dos quais a globalização afeta os sistemas jurídicos nacionais variam entre si, mas parece haver o consenso de que o Estado enquanto pólo centralizado de produção e controle jurídico resta prejudicado e diminuído. Não somente em autores nacionais encontramos conclusões desta natureza, mas também em autores estrangeiros como HABERMAS.

O enfoque de HABERMAS concentra-se na maneira em que Estado e democracia se relacionam e como esta relação encontra-se sob pressão nos tempos atuais.

Em seu diagnóstico, o Estado, a sociedade e a economia classicamente estariam configurados de forma coextensiva dentro das mesmas fronteiras nacionais, mas "o sistema econômico internacional, no qual os Estados traçam as fronteiras entre a economia interna e as relações de comércio exterior, transforma-se, na esteira da globalização dos mercados, numa economia transnacional". ${ }^{6}$

A globalização não rompe somente fronteiras econômicas, mas também traz consigo o rompimento de outras fronteiras comerciais, financeiras e culturais, como o comércio mundial, mercados financeiros e corporações multinacionais, com cadeias produtivas de alcance global, questões de política interna mundial, acordos de paz e violência organizada, crescentes correntes migratórias, novas mídias e novas redes de comunicação.

HABERMAS aponta especificamente três aspectos da privação de poder do Estado nacional: a) a perda da capacidade de controle estatal, b) os crescentes déficits de legitimação no processo decisório e c) a progressiva incapacidade de dar provas, com efeito legitimador, de ações de comando e de organização. Descrevamos cada um deles.

A perda de autonomia do Estado significa, entre outras coisas, que o Estado isolado não é mais suficientemente capaz, com suas próprias forças, de defender seus cidadãos de outros atores ou contra os efeitos em cadeia de tais processos, que têm origem fora de suas fronteiras, tais como questões ambientais, crime organizado, riscos de segurança de alta tecnologia, tráfico de armas, epidemias, acidentes nucleares, etc.

O segundo aspecto, a perda de legitimação do processo decisório, surge quando o círculo daqueles que tomam parte nas decisões democráticas não coincide com o círculo daqueles que são afetados por essas decisões (HABERMAS menciona o caso europeu da falta de legitimidade do processo decisório dos especialistas de Bruxelas). O Estado nacional, hoje integrado institucionalmente numa rede de alianças e regimes transnacionais, cria em alguns campos políticos equivalentes para as competências perdidas no plano nacional: "quanto mais graves e numerosas são as matérias reguladas no curso das negociações interestatais, tanto mais decisões políticas são subtraídas à formação democrática da opinião e da vontade, formação esta ancorada unicamente nas arenas nacionais". 7 
Com relação ao terceiro aspecto, temos uma situação de restrição da capacidade interventiva do Estado nacional como política social legitimadora. Nas palavras de HABERMAS: "um capital que, na busca de possibilidades de investimento e ganhos especulativos, está por assim dizer isento do dever de presença nacional e vagabundeia à solta pode utilizar sua opções de retirada como uma ameaça, tão logo um governo preocupado com a amplitude da demanda, com padrões sociais ou garantias de emprego onere em demasia a posição nacional". ${ }^{8}$ No diagnóstico habermasiano, em vários países europeus, a repressão da política por parte do mercado exprime-se no círculo vicioso de desemprego crescente, sistemas previdenciários de benefícios excessivos e contribuições minguantes.

Parece-nos que a afirmação de que o Estado nacional e seu papel jurídico estão em franco declínio frente à globalização é apressada e precisa ser melhor qualificada. Um dos graves problemas da análise sociológica é a transposição automática de conceitos e categorias de uso corrente na sociologia européia para se inferir conclusões acerca da realidade brasileira, levando os autores nacionais a conclusões, no nosso ponto de vista, precipitadas.

A análise precedente de HABERMAS não pode ser transposta imediatamente para o caso e a conjuntura brasileira. Não podemos esquecer que as preocupações desse autor, como ele mesmo já declarou, circunscrevem mais nitidamente os países europeus e a União Européia. ${ }^{9}$ Quando ele menciona Estado nacional, subentende-se o contexto europeu. Quando menciona as tensões entre decisões nacionais e supranacionais, refere-se às tensões, por exemplo, de inúmeros países europeus de abdicarem de suas centenárias moedas nacionais em favor do novo "euro". Os problemas que transcendem as fronteiras nacionais são problemas característicos da proximidade geográfica dos países europeus, como acidentes nucleares, e.g. Chernobyl, que em alguns casos não fazem sentido em um país de dimensões continentais como o Brasil.

O perigo da transposição imediata das análises da globalização e sua aplicação à conjuntura brasileira, como na maioria dos casos tem sido feito, apresenta efeitos negativos. Como bem coloca PAULO NOGUEIRA BATISTA JR., "ajuda a mascarar a

8 Ibidem, p. 4.

9 As declarações de SÉRGIO PAULO ROUANET acerca da transposição das categorias da análise de HABERMAS ao Brasil podem ajudar a esclarecer o nosso argumento: "Para HABERMAS, ainda existem brechas de racionalidade sistêmica. Muito bem, em que eu acho que isso seria aplicável num país como o Brasil? Vimos que essa racionalidade comunicativa só se desdobra com o advento da modernidade. Ora, no Brasil coexistem um mundo pré-moderno e um mundo moderno, não é verdade? Há uma economia capitalista moderna que funciona, bem ou mal, de acordo com esses critérios de racionalidade sistêmica, há um estado burocrático e uma economia capitalista. Há ainda esferas inteiras que não emergiram sequer para a modernidade. Há dois mundos do silêncio, na verdade, na sociedade brasileira. Há o silêncio pré-moderno - nós vimos que, na verdade, não havia essa linguagem, essa comunicação, nas sociedades tradicionais, porque você tinha a lei da tradição, etc. Na sociedade brasileira, com esse silêncio pré-moderno, as pessoas que não emergiram para o mundo pleno e plural da linguagem e da ação comunicativa (...) E há ao mesmo tempo o silêncio sistêmico. Há áreas de racionalidade, de uma economia extremamente complexa e de um Estado já bastante complexo, onde, de novo, existe um silêncio, que é o silêncio do sistema. Há, então, um silêncio pré-moderno e um silêncio sistêmico". Folha de São Paulo, Folhetim, entrevista com BARBARA FREITAG e SÉRGIO PAULO ROUANET, p. B4-B5. 
responsabilidade pelas opções e decisões dos governos, obstruindo a crítica das políticas públicas. Por outro, inibe a reflexão sobre as alternativas de que dispõem os países na definição de suas políticas econômicas, sociais e de inserção internacional, contribuindo para imobilizar as iniciativas nacionais". ${ }^{10}$

Será realmente que uma afirmação tão categórica como a de que o Estadonação está em nítido declínio é necessariamente verdadeira? Há autores que discordam dessa assertiva e que trazemos à tona para o enriquecimento do debate.

Um deles é, como já citado, PAULO NOGUEIRA BATISTA JR. Em um interessante trabalho ${ }^{11}$ de cunho econômico-político, publicado na Revista do Instituto de Estudos Avançados da USP, ele denominou os cinco "mitos da globalização". Transcreveremos o principal argumento do autor que contraria cada mito:

\section{Mito $\mathbf{n}^{0} 1$}

A globalização inaugura nova etapa histórica econômica mundial; constitui processo irreversível, que conduziu a uma integração sem precedentes das economias nacionais:

"Muitos dos fenômenos apresentados para sugerir o advento de uma nova era constituem a reprodução, sob nova roupagem, de tendências antigas. 'Globalização' é uma nova palavra para um processo que remonta, em última análise, à expansão da civilização européia desde o final do século XV. A internacionalização econômica dos últimos 20 ou 30 anos tem precedentes históricos, notadamente nas décadas anteriores à Primeira Guerra. Em diversos aspectos, o grau de integração internacional alcançado entre 1870 e 1914 é comparável, ou até superior, ao observado na economia 'globalizada' do final do século XX. A ilusão de que estamos experimentando um processo inteiramente inédito de internacionalização se deve, em parte, ao fato de que a integração internacional recente é, de fato, significativa quando comparada ao baixo grau de abertura das economias logo após a Segunda Guerra. Perde-se de vista que, entre 1914 e 1945, as guerras, a grande depressão e o protecionismo destruíram o sistema internacional da belle époque, acontecimento que bem mereceria a reflexão dos que acreditam na irreversibilidade dos processo históricos." 12

\section{Mito $\mathrm{n}^{\mathrm{O}} 2$}

Nas últimas duas ou três décadas, a globalização econômica produziu um sistema econômico fortemente integrado, de caráter supranacional, que tende inexoravelmente

10 BATISTA JR., Paulo Nogueira. Mitos da "globalização", p. 179. Cf. também acerca dos mitos da globalização a obra de PAUL HIRST e GRAHAME THOMPSON, Globalização em questão: a economia internacional e as possibilidades de governabilidade.

11 Ibidem, p. 180-182. O artigo é bastante extenso e detalhado; aqui apenas reproduzimos as principais conclusões do autor. Remetemos o leitor interessado em mais detalhes, como tabelas e comparação de dados, à sua leitura.

12 Ibidem, p. 180. 
a unificar o mercado mundial, a dissolver as fronteiras nacionais e a reduzir a relevância dos mercados domésticos:

"O processo de internacionalização observado nas décadas recentes não tem o alcance e muito menos o caráter universal sugerido pelo uso indiscriminado do termo 'globalização'. Está muito longe de provocar o desaparecimento das fronteiras ou ameaçar a sobrevivência do Estado nacional. É verdade que o progresso técnico e as inovações em áreas como informática, telecomunicações e finanças, combinados com a liberalização de mercados e a remoção de restrições a operações internacionais, vêm contribuindo para a maior integração das economias nacionais. Não obstante, os mercados internos continuam a preponderar, por larga margem, na absorção da produção, na geração de empregos e no financiamento dos investimentos. Além disso, os mercados de trabalho permanecem altamente segmentados por políticas restritivas de imigração e outros obstáculos à movimentação internacional de trabalhadores. Os dados sobre a distribuição geográfica dos fluxos de comércio internacional e dos movimentos de capital também não confirmam a propalada imagem de uma economia 'global' ou de um mercado mundial unificado. O quadro é de forte concentração das atividades internacionais nos países desenvolvidos, que respondem por dois terços ou mais dos fluxos de comércio e de capital. A própria expressão 'globalização' é enganosa e deve ser evitada. É preferível utilizar termos como 'economia internacional' ou 'internacionalização econômica', mais compatíveis com um quadro mundial caracterizado, fundamentalmente, pelo intercâmbio entre economias nacionais distintas."

\section{Mito $\mathbf{n}^{\mathrm{o}} 3$}

Em conseqüência da globalização e do predomínio das políticas "neoliberais", os Estados nacionais entraram em processo de inevitável declínio e estão sendo compelidos a reduzir a sua presença na economia:

"O predomínio ideológico do chamado neoliberalismo - que apesar do prefixo constitui uma tentativa de restaurar o ideário econômico do século XIX - não chegou a modificar de maneira significativa e duradoura a dimensão do Estado na grande maioria das economias desenvolvidas. Não chegou sequer a interromper a tendência de aumento do peso do governo, medido por indicadores agregados, como a relação entre a despesa e a receita públicas e o PIB. O exame dos dados macroeconômicos das economias desenvolvidas indica que há uma enorme distância entre o discurso 'neoliberal' e a realidade dos países onde essa ideologia teve origem." 14

Mito $n^{0} 4$

A "economia global" vem sendo crescentemente dominada por empresas "transnacionais", livres de identificação e lealdades nacionais: 
"A grande maioria das empresas permanece marcada por sua origem nacional. Corporações verdadeiramente transnacionais são raras, especialmente nas economias de maior porte, que contam com amplos mercados internos. Não há dúvida de que nas últimas décadas as empresas dos países desenvolvidos, e mesmo de alguns países em desenvolvimento, ampliaram as suas atividades no exterior e passaram a desenvolver uma parte das suas atividades fora de seu país de origem. Mas isso não significa que as firmas perderam as suas referências e vínculos nacionais. A grande maioria delas mantém o grosso dos seus ativos, vendas e empregos na sua base nacional. As atividades geradoras de maior valor adicional e funções estratégicas, como pesquisa e desenvolvimento, tendem a se realizar no país de origem das empresa. Em geral, as corporações não devem ser caracterizadas como 'transnacionais' ou 'multinacionais', mas sim como firmas nacionais com operações internacionais." $" 15$

\section{Mito $n^{\circ} 5$}

A expansão das transações financeiras internacionais criou um mercado "global" de capitais extraordinariamente poderoso, diante do qual a autonomia das políticas nacionais e dos bancos centrais, mesmo nos países de mais peso, tende a desaparecer:

"O grau de internacionalização das finanças é mais limitado do que sugere o uso indiscriminado de expressões como 'globalização financeira' ou 'mundialização do capital financeiro'. A despeito da acentuada expansão das operações financeiras internacionais, as aplicações domésticas ainda são largamente predominantes. O comportamento dos investidores institucionais dos países desenvolvidos, particularmente dos fundos de pensão e das companhias de seguro, revela um forte viés em favor dos mercados domésticos. A preponderância dos mercados nacionais também aparece de forma esmagadora nos dados referentes aos mercados de títulos e ações. Por esses e outros motivos, é prematuro admitir a existência de um mercado global de capitais. É verdade que o aumento do volume e da velocidade das transações financeiras internacionais cria situações novas. Dificulta, por exemplo, a sustentação de certos tipos de regime cambial, especialmente daqueles que se caracterizam por alguma forma de ancoragem flexível, a exemplo do regime adotado pelo Brasil nos anos recentes. Não é por acaso que tem havido nas décadas recentes uma tendência marcada para a flutuação cambial administrada, não só nos países desenvolvidos, como também nos países em desenvolvimento, pois esse é o tipo de regime cambial que permite conciliar o crescimento das operações financeiras internacionais com a preservação da autonomia dos bancos centrais na busca de objetivos domésticos. Longe de estarem reduzidos à condição de atores secundários, os bancos centrais continuam e continuarão a preservar a sua autonomia e a exercer forte influência sobre os mercados de 
câmbio, agindo isoladamente ou em intervenções coordenadas com outros bancos centrais." 16

Pelas conclusões de PAULO NOGUEIRA BATISTA JR., a globalização transformou-se num mito moderno muito mal avaliado nos países em desenvolvimento, gerando expectativas negativas para o futuro do constitucionalismo.

Se suas conclusões forem verdadeiras, não há por que inferir que realmente o constitucionalismo brasileiro está em crise, derivado da crise de legitimação e poder do Estado e da conseqüente perda da força normativa da Constituição. O Estado nacional, apesar de não parecer, ainda permanece como sendo o pólo principal de produção jurídica e controle social.

Depois dos atentados de 11 de setembro de 2001 ao World Trade Center, é possível visualizar como o Estado manifesta atualmente sua força e seu controle. Como negar seu poder na restrição norte-americana à imigração, na suspensão dos direitos civis aos estrangeiros, na instalação de tribunais militares, na adoção de medidas comercialmente protecionistas na administração BUSH $?^{17}$ Na Europa também podemos encontrar situações semelhantes. Recentemente a Áustria instituiu como medida obrigatória o aprendizado do idioma alemão a todos os imigrantes residentes. A contradição do sistema atual parece estar no fato de que quanto mais as mercadorias devam circular livremente, menos as pessoas o possam fazer.

Ou seja, as notícias comuns dos jornais nos indicam que nestes tempos de globalização o Estado ainda manifesta, em alguns casos com muita intensidade, o seu leviatânico poder.

Assumir a globalização como uma força inevitável é mascarar a realidade no caso brasileiro. Se a nossa Constituição está em crise, dezenas de vezes emendada, devemos procurar as razões internamente e não atribuí-las às pressões que vêm de fora. A soberania estatal ainda é o instrumento mais eficaz com o qual podemos contar para efetivar as normas constitucionais e nos posicionar frente à conjuntura internacional.

É curioso que no Brasil, antes de termos chegado a um sistema de ensino universal e de qualidade, estejamos reservando cotas para minorias nas universidades, como já implantado na Universidade Estadual do Rio de Janeiro. A natureza da discriminação nos Estados Unidos é qualitativamente diferente da que ocorre no Brasil. Possuir um sistema educacional formalmente acessível a todos e discriminar é radicalmente diferente do sistema brasileiro, no qual a minoria possui acesso ao sistema educacional universitário e a maioria, seja ela negra ou não, resta excluída do sistema. Ações afirmativas não resolvem o problema da discriminação maior que está na base do sistema, incapaz de concretizar o direito constitucional à educação.

Caberia aqui lembrar uma citação de KELSEN, que, ao escrever sobre democracia, lembrou a importância do sistema burocrático para a consolidação desta:

"Esta é a razão profunda pela qual, mesmo nas nações em que o princípio democrático está acima de qualquer contenda partidária, como, por exemplo,

16 Ibidem, p. 182.

17 Cf. a respeito da situação política norte-americana atualmente, o artigo de JAMES PETRAS, professor de ética política na Universidade de Nova Iorque, "Uma nação de delatores". 
nos Estados Unidos, a burocratização aumenta na mesma proporção em que aumentam as tarefas administrativas do Estado, ou seja, suas funções executivas. Seria errôneo ver nisto simplesmente um enfraquecimento da democracia. De fato, democracia e burocracia parecem opor-se de modo absoluto apenas do ponto de vista ideológico, mas não se considerarmos a realidade. Ao contrário, burocratização significa, em certas condições, manutenção da democracia. $\mathrm{O}$ princípio democrático, na realidade, pode ser aplicado aos estratos superiores e não pode penetrar - sem pôr em dúvida a sua validade no campo da formação da vontade geral - nos estratos mais profundos de um processo em que o corpo do Estado se cria e renova incessantemente."18

Com exceção de alguns setores do Estado, temos ainda no Brasil uma burocracia em fase de desenvolvimento e ainda não consolidada. Não podemos esperar a concretização da democracia com um déficit burocrático. A tendência atual de supressão dos direitos sociais do nível constitucional não pode ser justificada como modernização das relações de trabalho decorrentes da globalização. A Itália, no começo deste ano, realizou uma ampla greve geral contra a supressão de alguns de seus direitos trabalhistas. Como justificar que podemos abrir mão desses direitos se ainda encontramos no Brasil relações de trabalho escravo ou trabalho infantil? Portanto, parece-nos que as razões para as crises crônicas do Estado brasileiro e da perda da força normativa da Constituição de 1988 estão menos na globalização do que no nosso passado colonial, periférico e dependente, aspirante a uma falsa e quase sempre ideológica modernização.

Esperamos responder negativamente à pergunta proposta no título deste item, citando PAULO BONAVIDES, que, como conclusão da evolução constitucional do Brasil, pontua: "A Constituição de 1988, ao revés do que dizem os seus inimigos, foi a melhor das Constituições brasileiras de todas as nossas épocas constitucionais. Onde ela mais avança é onde o Governo mais intenta retrogradá-la. Como constituição dos direitos fundamentais e da proteção jurídica da Sociedade, combinando assim defesa do corpo social e tutela dos direitos subjetivos, ela fez nesse prisma judicial do regime significativo avanço". ${ }^{19}$

\section{CONCLUSÃO}

Frente a um assunto que vem sendo amplamente discutido, mas nem sempre com a profundidade necessária, o principal argumento desenvolvido durante o trabalho foi a procura de uma desmistificação da globalização como novidade e da opinião de que alguns efeitos devem-se a ela, como o enfraquecimento da esfera de ação dos Estados nacionais.

Não duvidamos que tem ocorrido uma forte expansão das transações internacionais, especialmente no terreno financeiro, que o progresso técnico em áreas como a informática e as telecomunicações, associados à diminuição dos custos de 
transporte, tem favorecido a integração dos mercados nacionais e a internacionalização dos processos de produção em muitos setores da economia. No entanto, é preciso acautelar-se sobre reais efeitos e alcance destas transformações. Preferimos uma postura mais céptica que entusiasta desses não tão novos acontecimentos.

O mais preocupante e que precisa ser desmistificado é o argumento que encontra na globalização a justificativa maior para os problemas nacionais. Se o desemprego aumenta ou se as empresas nacionais são absorvidas por grupos estrangeiros, a justificativa são as exigências de competitividade em uma economia "globalizada". Se o país aparece vulnerável a turbulências financeiras externas, a culpa seria da instabilidade dos mercados financeiros "globais". Portanto, a ideologia da globalização aparece como a causa dos problemas internos e isenta os governantes de sua real responsabilidade.

O mesmo argumento, infelizmente, também pode ser encontrado no campo do direito constitucional. A globalização seria a causa da perda de eficiência da ação estatal e por conseqüência teríamos uma crise do poder normativo constitucional. $\mathrm{O}$ perigo desse argumento é repetir a falácia apontada no parágrafo anterior, buscando a causa da crise onde ela não está.

A principal conclusão que pretendemos ter formulado é que uma crise de legitimidade existe, mas sua causa não encontra-se verdadeiramente na globalização nem na perda do poder estatal de controle social. É preciso ainda fortalecer e aperfeiçoar, principalmente no Brasil, a burocracia estatal, a soberania da lei, o princípio da igualdade formal, dentre outros aspectos, para que a democracia possa ser consolidada.

\section{REFERÊNCIAS BIBLIOGRÁFICAS}

BATISTA JR., Paulo Nogueira. Mitos da globalização. Estudos Avançados, 12 (32), p. 125-186, 1998.

BOBBIO, Norberto. Direito e estado no pensamento de Immanuel Kant. 3. ed. Trad. Alfredo Fait. Rev. Estevão Rezende Martins. Brasília: Universidade de Brasília, 1995.

BONAVIDES, Paulo. A evolução constitucional do Brasil. Estudos Avançados, 14 (40), p. 155176, 2000. Conferência feita na Academia Piauense de Letras em 27 de julho de 2000.

FARIA, José Eduardo. Direitos humanos e globalização econômica: notas para uma discussão. Estudos Avançados, 11 (30), 1997, p. 43-53.

FREITAG, Barbara; ROUANET, Sérgio Paulo. Entrevista com Barbara Freitag e Sérgio Paulo Rouanet. Folha de São Paulo, Folhetim, n. 549, 14 de agosto 1987, p. B-2 a B-5.

HABERMAS, Jürgen. Nos limites do Estado. Trad. José Marcos Macedo. Jornal Folha de São Paulo, $5^{\circ}$ caderno Mais, 18 de julho, 1999, p. 4-6.

HIRST, Paul; THOMPSON, Grahame. Globalização em questão: a economia internacional e as possibilidades de governabilidade. Trad. Wanda Caldeira Brant. Petrópolis: Vozes, 1998.

KELSEN, Hans. A democracia. Trad. Ivone Castilho Benedetti et al. São Paulo: Martins Fontes, 1993.

PETRAS, James. Uma nação de delatores. Trad. Emílio Gennari. Caros Amigos, ano V, n. 59, fev. 2002, p. 25-29.

SARMENTO, Daniel. Constituição e globalização: a crise dos paradigmas do direito constitucional. Revista de Direito Administrativo, 215, jan./mar. 1999, p. 19-34. 